\title{
Ochratoxin A induces behavioral and neurochemical changes in adult zebrafish
}

Jéssica Valadas ${ }^{\mathrm{a}}$, Adrieli Sachett ${ }^{\mathrm{a}}$, Matheus Marcon ${ }^{\mathrm{c}}$, Leonardo M. Bastos ${ }^{\mathrm{b}}$, Angelo

Piato $^{\mathrm{a}, \mathrm{b}^{*}}$

a Programa de Pós-Graduação em Neurociências, Instituto de Ciências Básicas da Saúde, Universidade Federal do Rio Grande do Sul (UFRGS), Porto Alegre, RS, Brazil

${ }^{\mathrm{b}}$ Departamento de Farmacologia, Instituto de Ciências Básicas da Saúde, Universidade Federal do Rio Grande do Sul (UFRGS), Porto Alegre, RS, Brazil

${ }^{c}$ Departamento de Bioquímica, Farmacologia e Fisiologia, Universidade Federal do Triângulo Mineiro (UFTM), Uberaba, MG, Brazil

*Correspondence to:

Angelo Piato, Ph.D. Programa de Pós-graduação em Ciências Biológicas: Farmacologia e Terapêutica, Instituto de Ciências Básicas da Saúde, Universidade Federal do Rio Grande do Sul (UFRGS), Avenida Sarmento Leite, 500/305, Porto Alegre, RS 90050170, Brazil; Phone/Fax: +55 51 33083121; E-mail address: angelopiato@ufrgs.br 


\begin{abstract}
Ochratoxin A (OTA) is a mycotoxin produced by species of filamentous fungi widely found as a contaminant in food and with high toxic potential. Studies have shown that this toxin cause kidney and liver damage, however, data on the effects of exposure to OTA on the central nervous system are still scarce. Zebrafish (Danio rerio) is a teleost often used in translational research due to its physiological, genetic, and behavioral homology with mammals, in addition to being useful as an environmental bioindicator. Thus, this study aimed to investigate the effects of exposure to OTA on behavioral and neurochemical parameters in adult zebrafish. The animals were treated with different doses of OTA $(1.38,2.77$, and $5.53 \mathrm{mg} / \mathrm{kg})$ and submitted to behavioral evaluations in the open tank and social interaction tests. Subsequently, they were euthanized, and the brains were used to assess markers associated with oxidative status. In the open tank test OTA induced changes in distance, absolute turn angle, mean speed, and time-freezing. However, no significant effects were observed in the social interaction test. Moreover, OTA also induced alterations in neurochemical parameters with changes in non-protein thiols (NPSH), glutathione peroxidase (GPx), glutathione-S-transferase (GST), and glutathione reductase (GR). This study showed that OTA can affect neurobiological aspects in zebrafish even at low doses.
\end{abstract}

Keywords: Toxin, environmental contaminant, toxicology, oxidative status. 


\section{INTRODUCTION}

It is estimated that 200 thousand people are added daily to the world's demand for food (Nellemann et al., 2009). With the projections that by 2050 the world will reach 9.8 billion inhabitants (United Nations, 2017), the search for solutions to meet these needs becomes urgent. Currently, the tools used to solve this issue are responsible for creating other problems. For example, the increase of pesticides in large crops is already causing serious environmental and public health impacts (Langley and Mort, 2012; Rani et al., 2021; World Health Organization, 2006); Improperly tampering with livestock products has become a crime that puts consumers' lives in danger (Cavin et al., 2018; Xin and Stone, 2008); Industry investment in processed foods has been linked to the incidence of obesity, diabetes, celiac disease and heart disease (Aguayo-Patrón and Calderón de la Barca, 2017; Anand et al., 2015; Canella et al., 2014). Although for a long time, environmental conditions and inadequate storage of food products have been ignored, today it is already clear that these conducts are responsible for the increasing presence of mycotoxins (Marroquín-Cardona et al., 2014).

Mycotoxins are naturally occurring compounds in species of fungi and are potentially toxic (Tola and Kebede, 2016). Ochratoxin A (OTA) is a mycotoxin produced by filamentous fungi and belongs to the ochratoxin subgroup, along with ochratoxin B and C. However, OTA has more natural occurrence and higher toxicity than other ochratoxins. OTA has become a very common contaminant in food and the ecosystem. There is evidence of the presence of OTA in water sources (Hu et al., 2017; Mata et al., 2015) and sea animals (Sun et al., 2015). The highest incidence of detection, however, occurs in food. OTA has already been found in many types of food in the world, including meats found in Croatia (Pleadin et al., 2015), in Brazilian and European coffee (Almeida et al., 2007; v. d. Stegen et al., 1997), wines, and beers from Chile and Hungary (VARGA et al., 2014; Vega et al., 2012), fruits in Argentina and Canada (Lombaert et al., 2004; Magnoli et al., 2004), European juices (Jørgensen, 2005) and several other types of products across the globe.

The exportation market moves around billions of dollars per year (Food and Agriculture Organization (FAO), 2019b) and billions of food tons (Food and Agriculture Organization (FAO), 2019a) are transferred from some places in the world and transported to other countries with different laws and cultures. Most of those nations have protocols and specific regulations for the limits tolerable of contaminants 
in the food, including OTA (Bureau of Chemical Safety et al., 2009; Ministério da Saúde and Agência Nacional de Vigilância Sanitária, 2011; Official Journal of the European Union, 2006). However, there is no consensus on acceptable limits for this contaminant among countries and, as the trade develops, the OTA present in food crosses borders and easily spreads around the world due to lack of consent between health inspection standards.

The mechanism throughout OTA toxicity it's not clear yet. It is believed to be related to inhibition of proteins synthesis caused by the competition between the phenylalanine group of OTA and phenylalanine amino acid. Other pathways such as cellular energy production and genetic are also affected (Köszegi and Poór, 2016). The effects of OTA have already been evaluated in rodents (Castegnaro et al., 1998; Kanisawa and Suzuki, 1978), birds (Stoev, 2010), and fish (Doster et al., 1974; Manning et al., 2003). The toxin has been associated with immune modulation (Lea et al., 1989), hepatic (Qi et al., 2015), and kidney diseases (Abid et al., 2003; Fuchs and Peraica, 2005). OTA has also been increasingly associated with neuropsychiatric diseases (Brewer et al., 2013; V Sava et al., 2006a, 2006c; Yoon et al., 2009), however, despite the importance of these reports, there is still little information regarding the behavioral and neurochemical effects related to OTA on non-target organisms. Therefore, OTA is an important contaminant for both environment and food commodities, but there are still several gaps in the knowledge about the effects of that toxin in organisms.

Native from Asia, the zebrafish is a teleost that has high genetic and physiological homology with humans (Lieschke and Currie, 2007), by this reason, this species has been used as a research animal model for different lines such as embryology and development (Hao et al., 2013; Keller et al., 2008), oxidative stress (Choi et al., 2010; Marcon et al., 2018), behavior (Abozaid et al., 2020; Nabinger et al., 2021; Reis et al., 2020) and genetic (Nasevicius and Ekker, 2000; Falcão et al., 2021). Moreover, this aquatic animal is a very interesting environmental bioindicator used in toxicology and ecotoxicology research, due to its capacity to simulate the conditions of an animal in its natural ecosystem (Asharani et al., 2008; Park et al., 2020; Valadas et al., 2019). In this context, since zebrafish is a suitable environmental bioindicator used in toxicology research, this study aimed to investigate the behavior and neurochemical effects of OTA in adult zebrafish. 


\section{MATERIALS AND METHODS}

\section{Animals}

The experiments were performed using 96 adult short-fin wild-type zebrafish (Danio rerio, Hamilton, 1822) of both sexes (50:50 male:female ratio) obtained from the local commercial supplier were used at the protocols. The animals were housed in a maximum density of two fish per liter of water in 16-L tanks $(40 \times 20 \times 24 \mathrm{~cm})$ and under a 14-10-h day/night cycle for 10 days before any procedure. Water parameters such as $\mathrm{pH}(7.0 \pm 0.3)$, chlorine, ammonia $(<0.01 \mathrm{mg} / \mathrm{L})$, and temperature $\left(26^{\circ} \mathrm{C} \pm 2\right)$ were controlled. Fish were fed twice a day with commercial flake food (Poytara®, Brazil) and supplementation of brine shrimp (Artemia salina). After the behavior tests, the animals were euthanized by hypothermic shock $\left(2^{\circ}-4^{\circ} \mathrm{C}\right)$ followed by decapitation, according to the AVMA Guidelines for the Euthanasia of Animals (Leary and Johnson, 2020). All procedures were approved by the Universidade Federal do Rio Grande do Sul ethical committee (\#37761/2020). The protocols were reported following ARRIVE Guidelines 2.0 (Percie du Sert et al., 2020).

\section{Drugs}

Ochratoxin A (OTA) (CAS 303-47-9), dimethyl sulfoxide (DMSO) (CAS 6768-5), and tricaine (MS-222) (CAS 886-86-2) were obtained from Sigma-Aldrich (St. Louis, MO, USA). Sodium chloride solution 0.9\% (saline, ADV Farma, SP, Brazil) was obtained from a local commercial supplier. OTA was dissolved into DMSO (final concentration of $10 \%$ DMSO). The OTA doses were based on the LD50 for intraperitoneal injection on rainbow trout (Salmo gairdneri or Oncorhynchus mykiss) (Doster et al., 1972) since there are no similar studies on adult zebrafish. The established doses for OTA in this study were $1.38,2.77$, and $5.53 \mathrm{mg} / \mathrm{kg}$.

\section{Experimental procedures}

After the period of acclimatization to the laboratory environment, the animals were divided into the following experimental groups: Control (CTRL), DMSO, OTA $(1.38,2.77$, and $5.53 \mathrm{mg} / \mathrm{kg})$. Allocation to experimental groups followed 
randomization procedures with a computerized random number generator (random.org) and the procedure was performed by researchers blinded to the experimental group. The drugs for each experimental group were administered at the beginning of the experiment (at 0 hours) by intraperitoneal injections and the control group received saline. Briefly, the intraperitoneal injections were performed using a Hamilton Microliter ${ }^{\mathrm{TM}}$ Syringe (701 N $10 \mu \mathrm{L}$ SYR 26 s/2" /2) x Epidurakatheter $0.45 \times 0.85$ mm (Perifix ${ }^{\circledR}$ - Katheter, Braun, Germany) x Gingival Needle 30G/0.3 × $21 \mathrm{~mm}$ (GN injecta, SP, Brazil). The injection volume was $1 \mu \mathrm{L} / 100 \mathrm{mg}$ of animal weight. The animals were previously anesthetized by immersion in a solution of tricaine $(300 \mathrm{mg} / \mathrm{L})$ until loss of motor coordination and reduced respiratory rate. After the anesthesia, the animals were placed in a sponge soaked in water exposing the abdomen and the needle was gently inserted parallel to the spine in the abdomen's midline posterior to the pectoral fins. This procedure was conducted in approximately 10 seconds (Fig. 1A) (Bertelli et al., 2021).

Following drug administration, the fish returned to their respective experimental tanks and remained for 96 hours. The housing and feeding conditions of the experimental tanks were the same described for the laboratory housing tanks. After 96 hours of exposure, the animals were individually submitted to the open tank test (OTT). After this, the animals returned to the experimental tank and remained for 24 hours. Then, the animals were submitted to the social interaction test (SIT). Immediately after the SIT, the animals were euthanized, and the brains were dissected and homogenized for the neurochemical assays of the parameters associated with oxidative status. The neurochemical parameters analyses were: thiobarbituric acid reactive substance (TBARS), non-protein thiol (NPSH), glutathione peroxidase (GPx), glutathione-S-transferase (GST), and glutathione reductase (GR). The sex of the animals was confirmed after euthanasia by dissecting and analyzing the gonads.
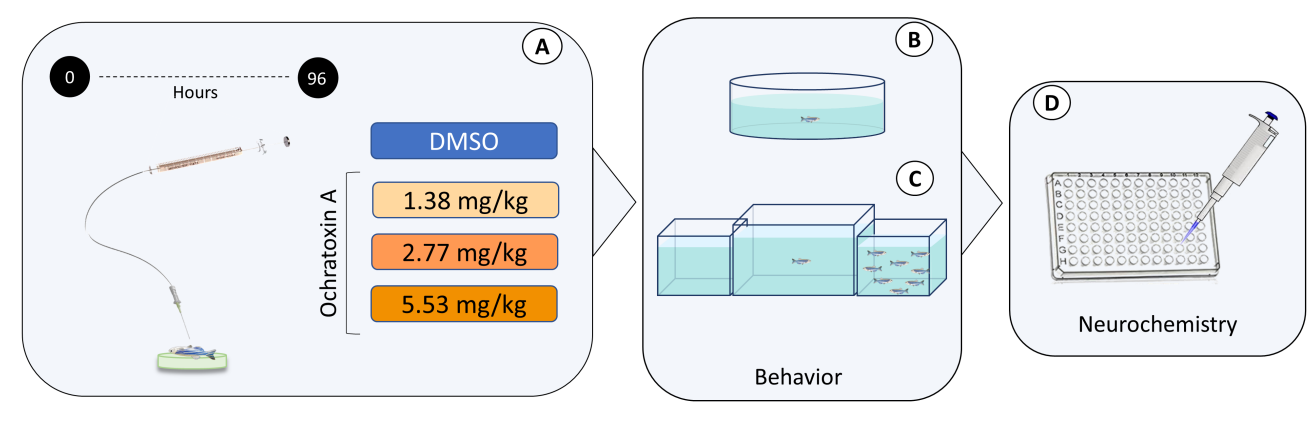

Figure 1. Experimental design. 


\section{Open tank test (OTT)}

The OTT consists of a white circular arena $(24 \mathrm{~cm}$ diameter, $8 \mathrm{~cm}$ height, and 2 $\mathrm{cm}$ water level). In this test, the animals were placed in the center of the arena and the behavior was individually recorded for $10 \mathrm{~min}$ (Fig. 1B). The videos were obtained from an upper view and for the analyses, the arena was virtually divided into two zones: center and periphery (Benvenutti et al., 2020). The following parameters were quantified using ANY-Maze software (Stoelting Co., USA): distance, crossings, absolute turn angle, mean speed, freezing episodes, and time-freezing duration.

\section{Social interaction test (SIT)}

In the SIT, fish were placed individually in a central tank $(30 \times 10 \times 15 \mathrm{~cm})$ flanked by two identical tanks $(15 \times 10 \times 13 \mathrm{~cm})$ and filmed from a frontal view for 7 min (Fig. 1C). One of the two tanks positioned beside the central tank (test tank) contained only water (neutral stimulus), and the other contained 10 zebrafish (social stimulus). All tanks were filled with water at a level of $10 \mathrm{~cm}$ and in the same conditions. The side of the social stimulus tank was counterbalanced to avoid any eventual bias (Benvenutti et al., 2020). The analyzes were carried out with the aid of the ANY-Maze software (Stoelting Co., USA), and for that, the test tank was virtually divided into three equal vertical zones (interaction, middle and neutral). The interaction zone was considered to be next to the tank that contained the social stimulus, while the neutral zone was considered to be next to the neutral stimulus. Animals were placed in the middle zone and had $2 \mathrm{~min}$ to habituate to the tank test. After this, the behavior was analyzed for $5 \mathrm{~min}$. The parameters quantified were distance, number of crossings, and interaction time.

\section{Neurochemical analysis}

Following the behavioral tests, the animals were euthanized by hypothermic shock $\left(2^{\circ}-4^{\circ} \mathrm{C}\right)$ and decapitation. The brains samples were then collected to evaluate the oxidative status (Fig. 1D). For each sample, a pool of 4 brains was used $(n=6)$ and mixed with $600 \mu \mathrm{L}$ of phosphate-buffered saline (PBS, pH 7.4, Sigma-Aldrich). The 
homogenate was centrifuged at $2400 \mathrm{~g}$ for $10 \mathrm{~min}$ at $4{ }^{\circ} \mathrm{C}$ and the supernatants were collected for the analyses of the following parameters: lipid peroxidation (TBARS) (Sachett, 2020), non-protein thiols (NPSH) (Sachett, 2020), and glutathione-Stransferase (GPx) (Sachett, 2021a), glutathione reductase (GR) (Sachett, 2021b) and glutathione-S-transferase (GST) (Habig and Jakoby, 1981).

\section{Statistical analysis}

The sample size was calculated with power analysis using $G^{*}$ Power 3.1.9.2 for Windows. Normality and homogeneity of variances were confirmed for all data sets using D'Agostino-Pearson and Levene tests, respectively. The student's t-test was performed to compare control and DMSO groups. One-way ANOVA followed by Tukey's post hoc test was used for the analyses. For behavioral data, the outliers were identified based on distance traveled using the ROUT statistical test (GraphPad ${ }^{\circledR}$ software) and were removed from the analyses. This resulted in 3 outliers ( 2 animals from the DMSO group and 1 animal from OTA $2.77 \mathrm{mg} / \mathrm{kg}$ group) removed from the OTT and 3 outliers ( 1 animal from the DMSO group, 1 from the $2.77 \mathrm{mg} / \mathrm{kg}$ group, and 1 from the $5.53 \mathrm{mg} / \mathrm{kg}$ group) removed from the SIT. The tank and sex effects were tested in all comparisons; The data were expressed as mean \pm standard deviation (S.D.). Differences were considered significant at $\mathrm{p}<0.05$.

\section{RESULTS}

DMSO did not show important modulation on behavior (Supplementary material 1) or induce oxidative damage (Supplementary material 2) compared with control sodium chloride. Therefore, we have used DMSO as a control group.

\section{Open tank test}

Fig. 2 shows the acute effects of OTA in adult zebrafish in the open tank test. There was a significant decrease in the distance (Fig. $2 \mathrm{~A}, \mathrm{p}=0.0105$ ), absolute turn angle (Fig. 2C, p = 0.0090), mean speed (Fig. 2D, p = 0.0110) and an increase in timefreezing (Fig. $2 \mathrm{~F}, \mathrm{p}=0.0052$ ) at the $1.38 \mathrm{mg} / \mathrm{kg}$ dose, indicating locomotor damage. 
The parameters of crossings and freezing episodes did not show significant changes in any dose.
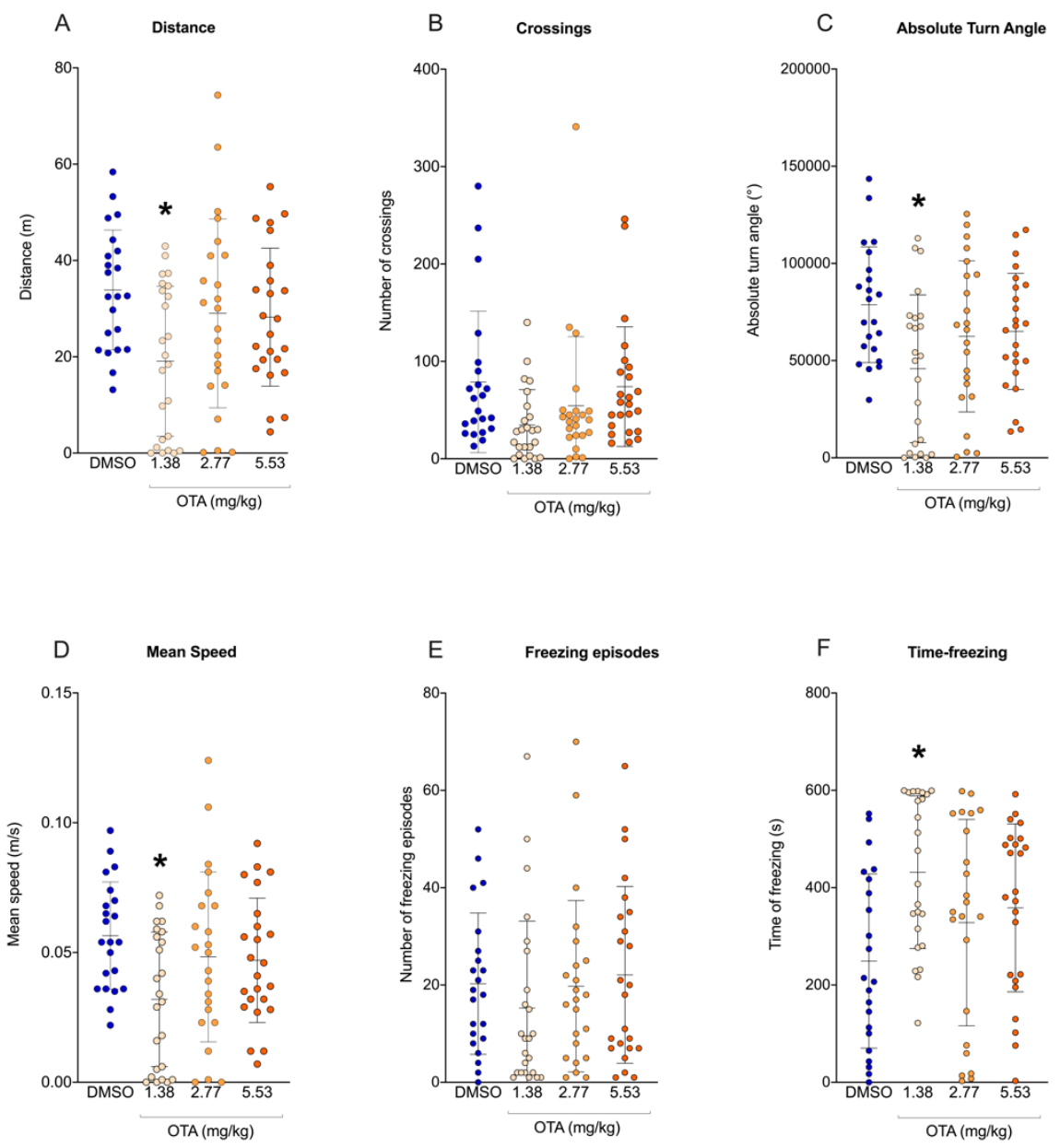

Figure 2. Effects of OTA in the open tank test. (A) distance, (B) crossings, (C) absolute turn angle, (D) mean speed, (E) freezing episodes, and (F) time-freezing. Data are expressed as mean \pm standard deviation (S.D.). $n=21-24$. One-way ANOVA followed by Tukey's post hoc test. $* \mathrm{p}<0.05$.

\section{Social interaction test}

Fig. 3 shows the acute effects of OTA on adult zebrafish at the SIT. OTA, in the tested doses, did not alter social behavior in any of the analyzed parameters. 

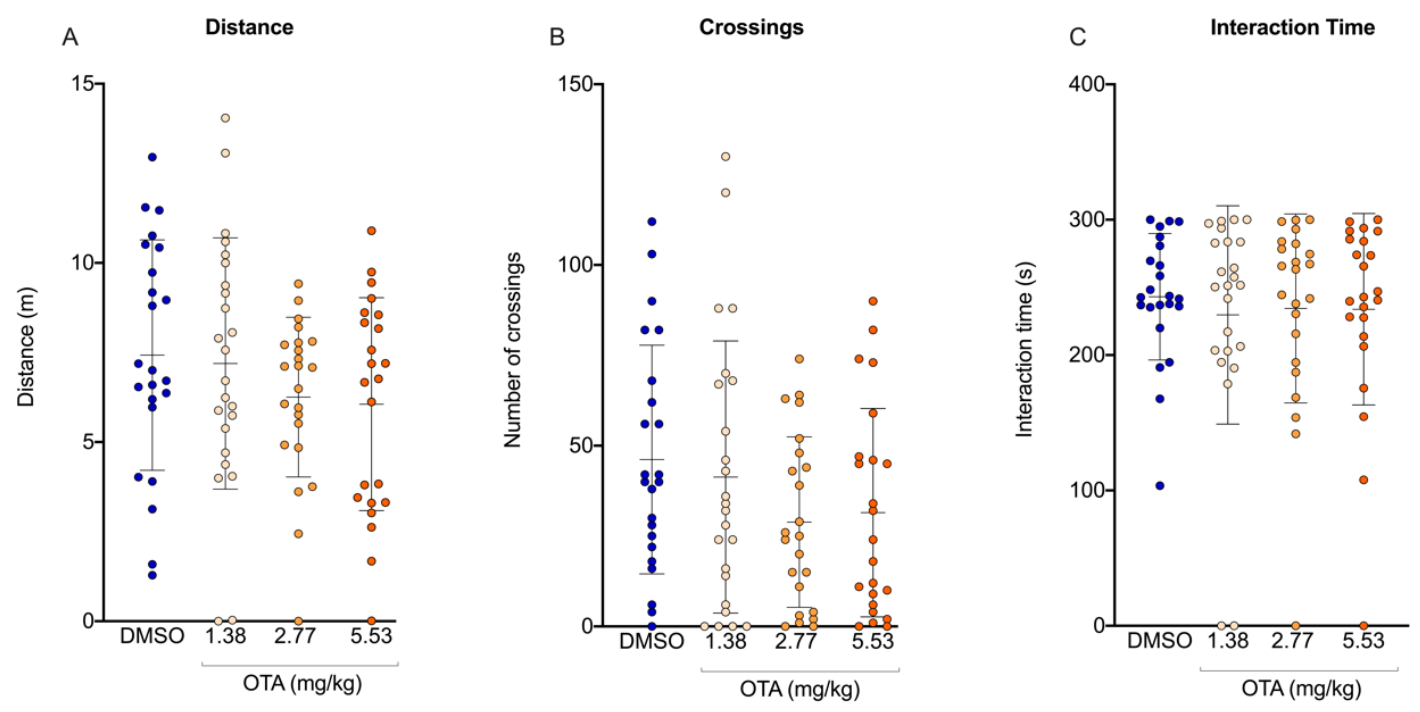

Figure 3. Effects of OTA in the social interaction test. (A) distance, (B) crossings, (C) interaction time. Data are expressed as mean \pm standard deviation (S.D.). $n=21-24$. One-way ANOVA.

\section{Neurochemical analysis}

Fig. 4 shows the effects of OTA on neurochemical parameters. OTA at 1.38 $\mathrm{mg} / \mathrm{kg}$ increased the GPx (Fig. 4C, p < 0.0001), GST (Fig. 4D, p $<0.0001$ ), and GR (Fig. 4E, $\mathrm{p}=0.0397$ ) activities. The intermediate dose of $2.77 \mathrm{mg} / \mathrm{kg}$ decreased NPSH levels (Fig. 4B, p=0.0006) and increased GPx (Fig. 4C, p=0.0016) and GST (Fig. 4D, $\mathrm{p}=0.0146)$ activities. The dose of $5.53 \mathrm{mg} / \mathrm{kg}$ increased GPx (Fig. 4C, $\mathrm{p}<0.0001)$ and GR (Fig. 4E, $\mathrm{p}=0.0238$ ) activities. 

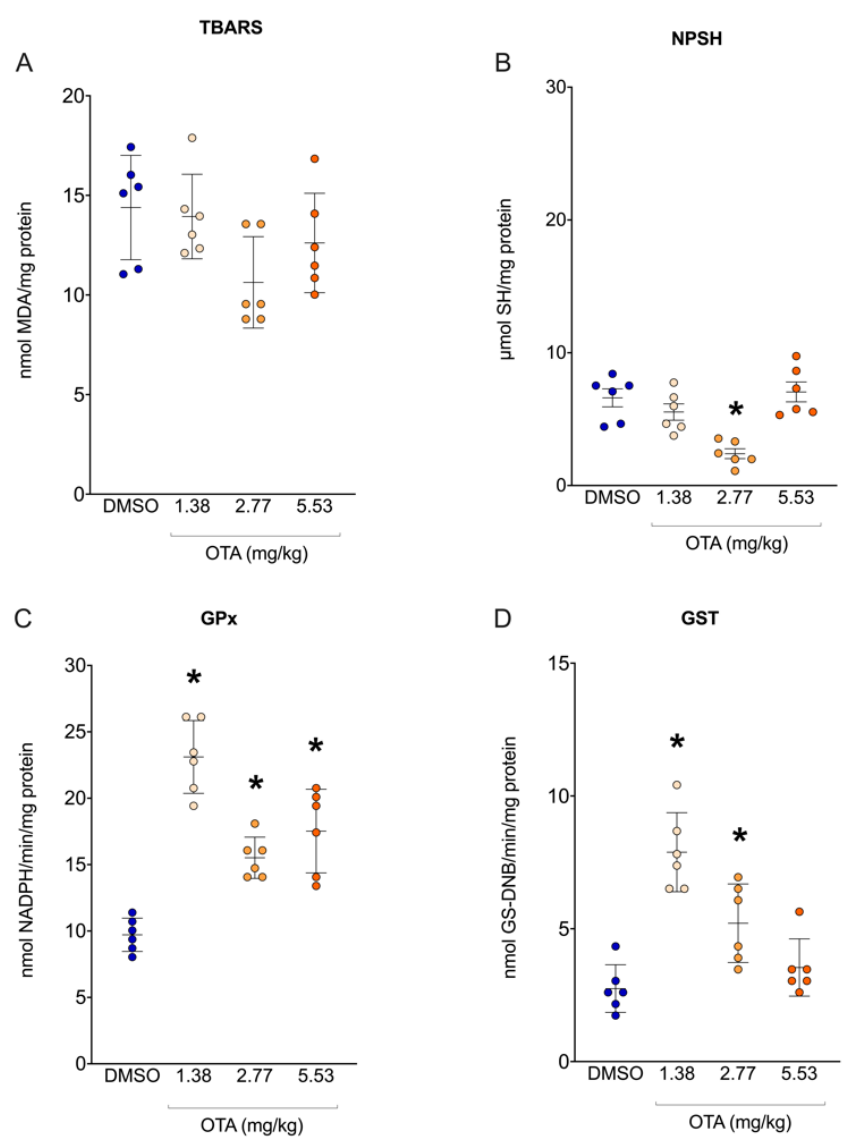

D

GST

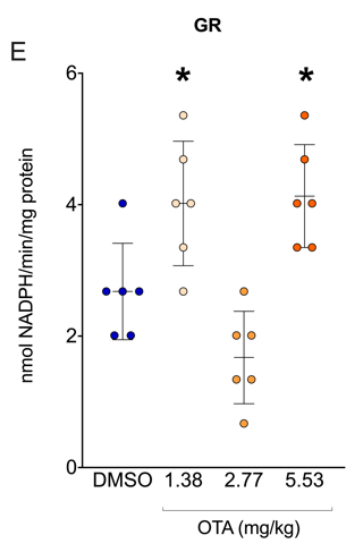

Figure 4. Effects of OTA in neurochemical parameters. (A) TBARS, (B) NPSH, (C) GPx, (D) GST, and (E) GR. Data are expressed as mean \pm standard deviation (S.D.). $\mathrm{n}=$ 6. One-way ANOVA followed by Tukey's post hoc test. *p $<0.05$.

\section{DISCUSSION}

This study showed the deleterious effects of ochratoxin A in adult zebrafish. Briefly, the toxin decreased the total distance traveled, average speed, absolute turn angle and increased the freezing time. However, in the social interaction test, there were no behavioral changes in the evaluated parameters. Neurochemical analysis showed that 
the compound was able to generate alterations in the oxidative status that were not enough to alter TBARS but were able to trigger the oxidative defense system.

There are little data in the literature on the behavioral effects of OTA exposure not only in fish but this lack of information also extends to other animals. In zebrafish larvae, OTA decreased the animals' swimming speed but did not change parameters of distance and time spent active (Khezri et al., 2018). In rodents, it was shown that OTA injected intraperitoneally was able to cause behavioral changes in gait analysis, spontaneous activity, cylinder test, and pole test, similar to Parkinsonian symptoms that were stabilized with the use of L-Dopa (Bhat et al., 2018).

In our study, the interference of OTA on locomotion parameters in zebrafish was shown in the open tank test similar to the results previously cited in other models. A possibility for these findings could be the link between locomotion and the nigrostriatal pathway that has already been reported to be affected by OTA in rodent models (V. Sava et al., 2006; V Sava et al., 2006b). However, there were no changes in social interaction parameters. The social behavior in zebrafish presents a schooling cohesion that aims to search for food, escape from predators and reproduce (Pitcher, 1993). Thus, being a model closely linked to social functions, the zebrafish has been extensively studied for this type of behavior (Buske and Gerlai, 2011; Dreosti et al., 2015; Scerbina et al., 2012). However, precisely because socialization is genetically preserved and has an ontogenic nature in zebrafish, it may be a parameter less vulnerable to milder modulations such as those shown in this study, since the lowest concentration used was about $25 \%$ of the LD50 established in another model. Another aspect to be considered is related to the cues provided by the apparatus since previous studies have already demonstrated the multifactorial character of social behavior in zebrafish being linked to visual cues (Engeszer et al., 2007), olfactory cues (Gerlach et al., 2007) and also sensitive to alarm substances released by co-specifics (Canzian et al., 2017). The apparatus used in this study, however, only allowed the visual cues to be transmitted to the animal, so it is uncertain to say what the effects of OTA would be under other parameters involved in the animal's social behavior.

With increasing global concern about the spread of mycotoxins, the effect of these compounds on oxidative stress parameters has become a very debated issue (da Silva et al., 2018; Mavrommatis et al., 2021), with emphasis on ochratoxin A (Sorrenti et al., 2013; Tao et al., 2018). OTA can interact with peroxidases that produce a phenoxyl radical from OTA. Glutathione $(\mathrm{GSH})$ is capable of turn the phenoxyl radical 
into OTA again by forming a superoxide anion radical $\left(\mathrm{O}_{2}{ }^{--}\right)$that results in hydrogen peroxide $\left(\mathrm{H}_{2} \mathrm{O}_{2}\right) \cdot \mathrm{H}_{2} \mathrm{O}_{2}$ by Fenton reaction produces a hydroxyl radical $\left(\mathrm{OH}^{*}\right)$ that is responsible for oxidative damage (Adlouni et al., 2000). Another common pathway for OTA is the formation of an OTA- $\mathrm{Fe}^{3+}$ complex that is reduced in OTA- $\mathrm{Fe}^{2+}$ by cytochrome $\mathrm{P} 450$ resulting in $\mathrm{OH}^{\bullet}$ (Rahimtula et al., 1988). Several studies report the imbalance of oxidative status caused by the compound. In zebrafish larvae, there was the formation of reactive oxygen species (ROS) proportional to the increase in OTA concentration (Tschirren et al., 2018). A study with tambaqui (Colossoma macropomum), a freshwater fish, found an increase in the ROS and lipid peroxidation in the animal's muscles, as well as a decrease in the activity of antioxidant enzymes superoxide dismutase (SOD) and GPx (Baldissera et al., 2020). Similarly, an increase in lipid peroxidation and antioxidant enzymes activity catalase (CAT) and GR was seen with a decrease in SOD activity and GSH levels in the brain, kidney, and liver of rats (Nogaim et al., 2020). A study found an increase in ROS formation, lipid peroxidation, and decreased GSH levels in kidney cells (Lee et al., 2018). However, studies with birds have shown that in long-term exposure antioxidant defenses can increase against oxidative imbalance, especially the glutathione redox system (Fernye et al., 2021; Kövesi et al., 2019). Also, a study with Caenorhabditis elegans shown an increase in the expression of SOD and CAT in wine containing OTA (Schmidt et al., 2020). These studies collaborate with our results which showed that, in adult zebrafish, there was an increase in enzyme defenses with an elevation of GPx, GR, and GST, especially at the lowest dose. In the intermediate dose, there was no increase in GR as occurred in the other doses, which is consistent with the decrease in GSH levels (NPSH) in this group since GR is responsible for the recycling of glutathione, which is essential for the maintenance of antioxidant levels. The increase in GPx under these conditions indicates an attempt to control a possible increase in reactive oxygen species since GPx reduces $\mathrm{H}_{2} \mathrm{O}_{2}$ through the GSH oxidation, something quite common to occur in OTA exposures as mentioned in previous studies. The increase of GST activity also indicated an increase in OTA metabolization and elimination since GST catalyzes the conjugation of the reduced form of glutathione to xenobiotic substrates for detoxification. Likewise, this activation of defenses prevented the increase of ROS levels and consequently avoiding lipid peroxidation (TBARS levels) (Dasuri et al., 2013; Gandhi and Abramov, 2012). 
Despite the zebrafish being a model used for decades in research in several areas, many gaps still exist about the model, especially in the area of toxicology. In recent years there has been a considerable increase in studies in this field due to initiatives to standardize this type of analysis in fish (Gonçalves et al., 2020), including the OECD protocols (OECD Guidelines for the Testing of Chemicals, 1992). However, for adult animals, the methodologies tend to be limited to direct exposure to the animals' water, which is not suitable for all protocols. In the case of OTA, the formulation of the compound and the difficulty in storing or disposing of waste made this type of exposure impracticable so the intraperitoneal injection standardized in the laboratory was chosen. The use of intraperitoneal injection to assess the effects of OTA has already been used in other models, being effective in detecting deleterious effects on the metabolism mechanism in rats (Størmer et al., 1985) and neurotoxicity in the development of mice (Miki et al., 1994; Tamaru et al., 1988). In fish, OTA was injected peritoneally into rainbow trout (Salmo gairdneri) acutely (96 hours) for toxicological evaluation by histology and determination of LD50 (5.53 mg/kg) (Doster et al., 1974). However, these data were never detailed in other species and the use of zebrafish to evaluate the effects of OTA remained limited with little information regarding the effects of the toxin in this species.

Due to these important gaps in the literature, another point to be clarified is the dose-response reaction of zebrafish against OTA. In this study, the doses that were more behaviorally and neurochemically reactive were the lowest doses, with the highest dose changing few parameters in oxidative status. Thus, in this study, we speculate that OTA showed a hormetic effect in adult zebrafish. Hormesis is a biphasic dose-response characterized by stimulation at low doses and inhibition at high doses (Calabrese and Baldwin, 2002). For OTA, this type of curve has already been reported in an in vitro study ( $\mathrm{Li}$ et al., 2014), however, this is the first time that this behavior has been seen in an in vivo model. A biphasic curve can indicate the biological plasticity of the target organism (Calabrese and Mattson, 2011), and the zebrafish is a widely studied model precisely because of its capacity for neuroplasticity and regeneration (Cosacak et al., 2015; Ghosh and Hui, 2016). Thus, it is possible that the hormetic behavior of OTA, in this case, is linked to the animal's biological characteristics. Moreover, hormetic curves often occur with endocrine disruptors (Vandenberg et al., 2012) and other studies have demonstrated the potential of OTA to interfere with hormone production (Frizzell et al., 
2013; Woo et al., 2013). For all these reasons, toxicological results for low doses should not be ignored.

\section{CONCLUSION}

Although concern about controlling OTA levels is increasing, more efforts are still needed. For this, understanding the effects of the toxin on organisms is essential. This study demonstrated the potential that the toxin has for causing deleterious effects in adult zebrafish through behavioral change and neurochemical modulation, however, more studies are needed to elucidate the compound's mechanism of action and its effects on other organisms to further contribute to the field of toxicology and environment.

\section{ACKNOWLEDGMENTS}

We thank the Coordenação de Aperfeiçoamento de Pessoal de Nível Superior Brasil (CAPES), Conselho Nacional de Desenvolvimento Científico e Tecnológico (CNPq, proc. 303343/2020-6), and Pró-Reitoria de Pesquisa (PROPESQ) at Universidade Federal do Rio Grande do Sul (UFRGS) for funding.

\section{AUTHOR CONTRIBUTIONS}

All authors had full access to all the data in the study and take responsibility for the integrity of the data and the accuracy of the data analysis. Conceptualization, J.V. and A.P.; Methodology, J.V., A.S., M.M., L.M.B., A.P.; Investigation, J.V., A.S., M.M., L.M.B.; Formal Analysis, J.V., A.S., M.M., L.M.B., A.P.; Resources, A.P.; Writing Original Draft, J.V.; Writing - Review \& Editing, J.V., A.S., M.M., L.M.B., A.P.; Supervision, A.P.; Funding Acquisition, A.P.

\section{COMPETING INTERESTS}

The authors declare no competing interests. 


\section{REFERENCES}

Abid, S., Hassen, W., Achour, A., Skhiri, H., Maaroufi, K., Ellouz, F., Creppy, E., Bacha, H., 2003. Ochratoxin a and human chronic nephropathy in Tunisia: is the situation endemic? Human \& Experimental Toxicology 22, 77-84. https://doi.org/10.1191/0960327103ht328oa

Abozaid, A., Trzuskot, L., Najmi, Z., Paul, I., Tsang, B., Gerlai, R., 2020. Developmental stage and genotype-dependent behavioral effects of embryonic alcohol exposure in zebrafish larvae. Progress in Neuro-Psychopharmacology and Biological Psychiatry 97, 109774. https://doi.org/10.1016/j.pnpbp.2019.109774

Adlouni, C.E., Pinelli, E., Azemar, B., Zaoui, D., Beaune, P., Pfohl-Leszkowicz, A., 2000. Phenobarbital increases DNA adduct and metabolites formed by ochratoxin A: Role of CYP 2C9 and microsomal glutathione-S-transferase 35, 9 . https://doi.org/10.1002/(SICI)1098-2280(2000)35:2<123::AID-EM7>3.0.CO;2-L

Aguayo-Patrón, S.V., Calderón de la Barca, A.M., 2017. Old Fashioned vs. Ultra-ProcessedBased Current Diets: Possible Implication in the Increased Susceptibility to Type 1 Diabetes and Celiac Disease in Childhood. Foods 6. https://doi.org/10.3390/foods6110100

Almeida, A.P. de, Alaburda, J., Shundo, L., Ruvieri, V., Navas, S.A., Lamardo, L.C.A., Sabino, M., 2007. Ochratoxin A in brazilian instant coffee. Brazilian Journal of Microbiology 38, 300-303. https://doi.org/10.1590/S1517-83822007000200022

Anand, S.S., Hawkes, C., de Souza, R.J., Mente, A., Dehghan, M., Nugent, R., Zulyniak, M.A., Weis, T., Bernstein, A.M., Krauss, R., Kromhout, D., Jenkins, D.J.A., Malik, V., Martinez-Gonzalez, M.A., Mozafarrian, D., Yusuf, S., Willett, W.C., Popkin, B.M., 2015. Food Consumption and its impact on Cardiovascular Disease: Importance of Solutions focused on the globalized food system. J Am Coll Cardiol 66, 1590-1614. https://doi.org/10.1016/j.jacc.2015.07.050

Asharani, P.V., Lian Wu, Y., Gong, Z., Valiyaveettil, S., 2008. Toxicity of silver nanoparticles in zebrafish models. Nanotechnology 19, 255102. https://doi.org/10.1088/0957$4484 / 19 / 25 / 255102$

Baldissera, M.D., Souza, C.F., da Silva, J.A., Barroso, D.C., Glória, E.M., Mesadri, J., Wagner, R., Baldisserotto, B., Val, A.L., 2020. Dietary ochratoxin A (OTA) decreases growth performance and impairs muscle antioxidant system and meat fatty acid profiles in juvenile tambaqui (Colossoma macropomum). Comparative Biochemistry and Physiology Part C: Toxicology \& Pharmacology 236, 108803. https://doi.org/10.1016/j.cbpc.2020.108803

Benvenutti, R., Gallas-Lopes, M., Sachett, A., Marcon, M., Strogulski, N.R., Rosa Reis, C.G., Chitolina, R., Piato, A., Herrmann, A.P., 2020. How do zebrafish respond to MK-801 and amphetamine? Relevance for assessing schizophrenia-relevant endophenotypes in alternative model organisms (preprint). Neuroscience. https://doi.org/10.1101/2020.08.03.234567

Bertelli, P.R., Mocelin, R., Marcon, M., Sachett, A., Gomez, R., Rosa, A.R., Herrmann, A.P., Piato, A., 2021. Anti-stress effects of the glucagon-like peptide-1 receptor agonist liraglutide in zebrafish. Progress in Neuro-Psychopharmacology and Biological Psychiatry 111, 110388. https://doi.org/10.1016/j.pnpbp.2021.110388

Bhat, P.V., Anand, T., Mohan Manu, T., Khanum, F., 2018. Restorative effect of 1-Dopa treatment against Ochratoxin A induced neurotoxicity. Neurochemistry International 118, 252-263. https://doi.org/10.1016/j.neuint.2018.04.003

Brewer, J.H., Thrasher, J.D., Straus, D.C., Madison, R.A., Hooper, D., 2013. Detection of mycotoxins in patients with chronic fatigue syndrome. Toxins 5, 605-617. https://doi.org/10.3390/toxins5040605

Bureau of Chemical Safety, Food Directorate, Canada Health Products, and Food Branch, 2009. Information Document on Health Canada's Proposed Maximum Limits (Standards) for the Presence of the Mycotoxin Ochratoxin A in Foods. 
Buske, C., Gerlai, R., 2011. Shoaling develops with age in Zebrafish (Danio rerio). Prog Neuropsychopharmacol Biol Psychiatry 35, 1409-1415. https://doi.org/10.1016/j.pnpbp.2010.09.003

Calabrese, E.J., Baldwin, L.A., 2002. Defining hormesis. Hum Exp Toxicol 21, 91-97. https://doi.org/10.1191/0960327102ht217oa

Calabrese, E.J., Mattson, M.P., 2011. Hormesis provides a generalized quantitative estimate of biological plasticity. J. Cell Commun. Signal. 5, 25-38. https://doi.org/10.1007/s12079011-0119-1

Canella, D.S., Levy, R.B., Martins, A.P.B., Claro, R.M., Moubarac, J.-C., Baraldi, L.G., Cannon, G., Monteiro, C.A., 2014. Ultra-Processed Food Products and Obesity in Brazilian Households (2008-2009). PLoS ONE 9, e92752. https://doi.org/10.1371/journal.pone.0092752

Canzian, J., Fontana, B.D., Quadros, V.A., Rosemberg, D.B., 2017. Conspecific alarm substance differently alters group behavior of zebrafish populations: Putative involvement of cholinergic and purinergic signaling in anxiety- and fear-like responses. Behavioural Brain Research 320, 255-263. https://doi.org/10.1016/j.bbr.2016.12.018

Castegnaro, M., Mohr, U., Pfuhl-Leszkowicz, A., Estève, J., Steinmann, J., Tillmann, T., Michelon, J., Bartsch, H., 1998. Sex- and strain-specific induction of renal tumors by ochratoxin A in rats correlates with DNA adduction. International Journal of Cancer 77, 70-75. https://doi.org/10.1002/(SICI)1097-0215(19980703)77:1<70::AIDIJC12>3.0.CO;2-D

Cavin, C., Cottenet, G., Cooper, K.M., Zbinden, P., 2018. Meat Vulnerabilities to Economic Food Adulteration Require New Analytical Solutions. CHIMIA International Journal for Chemistry 72, 697-703. https://doi.org/10.2533/chimia.2018.697

Choi, J.E., Kim, S., Ahn, J.H., Youn, P., Kang, J.S., Park, K., Yi, J., Ryu, D.-Y., 2010. Induction of oxidative stress and apoptosis by silver nanoparticles in the liver of adult zebrafish. Aquatic Toxicology 100, 151-159. https://doi.org/10.1016/j.aquatox.2009.12.012

Cosacak, M.I., Papadimitriou, C., Kizil, C., 2015. Regeneration, Plasticity, and Induced Molecular Programs in Adult Zebrafish Brain. BioMed Research International 2015, 110. https://doi.org/10.1155/2015/769763

da Silva, E.O., Bracarense, A.P.F.L., Oswald, I.P., 2018. Mycotoxins and oxidative stress: where are we? World Mycotoxin Journal 11, 113-134. https://doi.org/10.3920/WMJ2017.2267

Dasuri, K., Zhang, L., Keller, J.N., 2013. Oxidative stress, neurodegeneration, and the balance of protein degradation and protein synthesis. Free Radical Biology and Medicine 62, 170-185. https://doi.org/10.1016/j.freeradbiomed.2012.09.016

Doster, R.C., Sinnhuber, R.O., Pawlowski, N.E., 1974. ACUTE INTRAPERITONEAL TOXICITY OF OCHRATOXIN AND B DERIVATIVES IN RAINBOW TROUT (SALMO GAIRDNERI). Food and Cosmetics Toxicology 12, 499-505.

Doster, R.C., Sinnhuber, R.O., Wales, J.H., 1972. Acute intraperitoneal toxicity of ochratoxins $\mathrm{A}$ and $\mathrm{B}$ in rainbow trout (Salmo gairdneri). Food and Cosmetics Toxicology 10, 8592. https://doi.org/10.1016/S0015-6264(72)80049-X

Dreosti, E., Lopes, G., Kampff, A.R., Wilson, S.W., 2015. Development of social behavior in young zebrafish. Front. Neural Circuits 9. https://doi.org/10.3389/fncir.2015.00039

Engeszer, R.E., Da Barbiano, L.A., Ryan, M.J., Parichy, D.M., 2007. Timing and plasticity of shoaling behaviour in the zebrafish, Danio rerio. Animal Behaviour 74, 1269-1275. https://doi.org/10.1016/j.anbehav.2007.01.032

Fernye, C., Ancsin, Z., Balogh, K., Mézes, M., Erdélyi, M., 2021. Role of the glutathione redox system in the susceptibility of pheasants (Phasianus colchicus) to ochratoxin A. Acta Veterinaria Hungarica 69, 125-133. https://doi.org/10.1556/004.2021.00021

Food and Agriculture Organization (FAO), 2019a. FAOSTAT - Commodities by regions.

Food and Agriculture Organization (FAO), 2019b. FAOSTAT - Value of Agricultural Production. 
Frizzell, C., Verhaegen, S., Ropstad, E., Elliott, C.T., Connolly, L., 2013. Endocrine disrupting effects of ochratoxin A at the level of nuclear receptor activation and steroidogenesis. Toxicology Letters 217, 243-250. https://doi.org/10.1016/j.toxlet.2012.12.018

Fuchs, R., Peraica, M., 2005. Ochratoxin A in human kidney diseases. Food Additives \& Contaminants 22, 53-57. https://doi.org/10.1080/02652030500309368

Gandhi, S., Abramov, A.Y., 2012. Mechanism of Oxidative Stress in Neurodegeneration. Oxidative Medicine and Cellular Longevity 2012, 1-11. https://doi.org/10.1155/2012/428010

Gerlach, G., Hodgins-Davis, A., MacDonald, B., Hannah, R.C., 2007. Benefits of kin association: related and familiar zebrafish larvae (Danio rerio) show improved growth. Behav Ecol Sociobiol 61, 1765-1770. https://doi.org/10.1007/s00265-007-0409-z

Ghosh, S., Hui, S.P., 2016. Regeneration of Zebrafish CNS: Adult Neurogenesis. Neural Plasticity 2016, 1-21. https://doi.org/10.1155/2016/5815439

Habig, W.H., Jakoby, W.B., 1981. Assays for differentiation of glutathione S-Transferases, in: Methods in Enzymology, Detoxication and Drug Metabolism: Conjugation and Related Systems. Academic Press, pp. 398-405. https://doi.org/10.1016/S0076-6879(81)770538

Hao, R., Bondesson, M., Singh, A.V., Riu, A., McCollum, C.W., Knudsen, T.B., Gorelick, D.A., Gustafsson, J.-A., 2013. Identification of Estrogen Target Genes during Zebrafish Embryonic Development through Transcriptomic Analysis. PLoS ONE 8, e79020. https://doi.org/10.1371/journal.pone.0079020

Hu, M., Huang, P., Suo, L., Wu, F., 2017. Cetylpyridinium chloride functionalized silica-coated magnetite microspheres for the solid-phase extraction and pre-concentration of ochratoxin A from environmental water samples with high-performance liquid chromatographic analysis. Journal of Separation Science 40, 2431-2437. https://doi.org/10.1002/jssc.201601464

Jørgensen, K., 2005. Occurrence of ochratoxin A in commodities and processed food - A review of EU occurrence data. Food Additives and Contaminants 26-30. https://doi.org/10.1080/02652030500344811

Kanisawa, M., Suzuki, S., 1978. Induction of renal and hepatic tumors in mice by ochratoxin A, a mycotoxin. Gann 69, 599-600.

Keller, P.J., Schmidt, A.D., Wittbrodt, J., Stelzer, E.H.K., 2008. Reconstruction of Zebrafish Early Embryonic Development by Scanned Light Sheet Microscopy. Science 322, 1065-1069. https://doi.org/10.1126/science.1162493

Khezri, A., Herranz-Jusdado, J.G., Ropstad, E., Fraser, T.WK., 2018. Mycotoxins induce developmental toxicity and behavioural aberrations in zebrafish larvae. Environmental Pollution 242, 500-506. https://doi.org/10.1016/j.envpol.2018.07.010

Kőszegi, T., Poór, M., 2016. Ochratoxin A: Molecular Interactions, Mechanisms of Toxicity and Prevention at the Molecular Level. Toxins (Basel) 8. https://doi.org/10.3390/toxins8040111

Kövesi, B., Cserháti, M., Erdélyi, M., Zándoki, E., Mézes, M., Balogh, K., 2019. Long-Term Effects of Ochratoxin A on the Glutathione Redox System and Its Regulation in Chicken. Antioxidants 8, 178. https://doi.org/10.3390/antiox8060178

Langley, R.L., Mort, S.A., 2012. Human Exposures to Pesticides in the United States. Journal of Agromedicine 17, 300-315. https://doi.org/10.1080/1059924X.2012.688467

Lea, T., Steien, K., Stormer, F.C., 1989. Mechanism of ochratoxin A-induced immunosuppression. Mycopathologia 107, 153-159.

Lee, H.J., Pyo, M.C., Shin, H.S., Ryu, D., Lee, K.-W., 2018. Renal toxicity through AhR, PXR, and Nrf2 signaling pathway activation of ochratoxin A-induced oxidative stress in kidney cells. Food and Chemical Toxicology 122, 59-68. https://doi.org/10.1016/j.fct.2018.10.004

Li, Y., Zhang, B., He, X., Cheng, W.-H., Xu, W., Luo, Y., Liang, R., Luo, H., Huang, K., 2014. Analysis of Individual and Combined Effects of Ochratoxin A and Zearalenone on HepG2 and KK-1 Cells with Mathematical Models. Toxins (Basel) 6, 1177-1192. https://doi.org/10.3390/toxins6041177 
Lieschke, G.J., Currie, P.D., 2007. Animal models of human disease: zebrafish swim into view. Nat Rev Genet 8, 353-367. https://doi.org/10.1038/nrg2091

Lombaert, G.A., Pellaers, P., Neumann, G., Kitchen, D., Huzel, V., Trelka, R., Kotello, S., Scott, P.M., 2004. Ochratoxin A in dried vine fruits on the Canadian retail market. Food Additives and Contaminants 21, 578-585. https://doi.org/10.1080/02652030410001687681

Magnoli, C., Astoreca, A., Ponsone, L., Combina, M., Palacio, G., Rosa, C. a. R., Dalcero, A.M., 2004. Survey of mycoflora and ochratoxin A in dried vine fruits from Argentina markets. Letters in Applied Microbiology 39, 326-331. https://doi.org/10.1111/j.1472765X.2004.01583.x

Manning, B.B., Ulloa, R.M., Li, M.H., Robinson, E.H., Rottinghaus, G.E., 2003. Ochratoxin A fed to channel catfish ( Ictalurus punctatus ) causes reduced growth and lesions of hepatopancreatic tissue. Aquaculture 219, 739-750. https://doi.org/10.1016/S00448486(03)00033-4

Marcon, M., Mocelin, R., Sachett, A., Siebel, A.M., Herrmann, A.P., Piato, A., 2018. Enriched environment prevents oxidative stress in zebrafish submitted to unpredictable chronic stress. PeerJ 6. https://doi.org/10.7717/peerj.5136

Marroquín-Cardona, A.G., Johnson, N.M., Phillips, T.D., Hayes, A.W., 2014. Mycotoxins in a changing global environment - A review. Food and Chemical Toxicology 69, 220-230. https://doi.org/10.1016/j.fct.2014.04.025

Mata, A.T., Ferreira, J.P., Oliveira, B.R., Batoréu, M.C., Barreto Crespo, M.T., Pereira, V.J., Bronze, M.R., 2015. Bottled water: Analysis of mycotoxins by LC-MS/MS. Food Chemistry 176, 455-464. https://doi.org/10.1016/j.foodchem.2014.12.088

Mavrommatis, A., Giamouri, E., Tavrizelou, S., Zacharioudaki, M., Danezis, G., Simitzis, P.E., Zoidis, E., Tsiplakou, E., Pappas, A.C., Georgiou, C.A., Feggeros, K., 2021. Impact of Mycotoxins on Animals' Oxidative Status. Antioxidants (Basel) 10, 214.

https://doi.org/10.3390/antiox10020214

Ministério da Saúde, Agência Nacional de Vigilância Sanitária, 2011. RESOLUÇÃO Nº 7, DE 18 DE FEVEREIRO DE 2011.

Nabinger, D.D., Altenhofen, S., Peixoto, J.V., da Silva, J.M.K., Gerlai, R., Bonan, C.D., 2021. Feeding status alters exploratory and anxiety-like behaviors in zebrafish larvae exposed to quinpirole. Progress in Neuro-Psychopharmacology and Biological Psychiatry 108, 110179. https://doi.org/10.1016/j.pnpbp.2020.110179

Nasevicius, A., Ekker, S.C., 2000. Effective targeted gene 'knockdown' in zebrafish. Nature Genetics 26, 216-220. https://doi.org/10.1038/79951

Nellemann, C., United Nations Environment Programme, GRID--Arendal (Eds.), 2009. The environmental food crisis: the environment's role in averting future food crises: a UNEP rapid response assessment. UNEP, Arendal, Norway.

Nogaim, Q.A., Sai Pratyusha Bugata, L., Pv, P., Reddy, U.A., P, M.G., S, I.K., M, M., 2020. Protective effect of Yemeni green coffee powder against the oxidative stress induced by Ochratoxin A. Toxicology Reports 7, 142-148. https://doi.org/10.1016/j.toxrep.2019.11.015

Official Journal of the European Union, 2006. COMMISSION REGULATION (EC) No 1881/2006 of 19 December 2006 setting maximum levels for certain contaminants in foodstuffs.

Park, S., Lee, J.-Y., You, S., Song, G., Lim, W., 2020. Neurotoxic effects of aflatoxin B1 on human astrocytes in vitro and on glial cell development in zebrafish in vivo. Journal of Hazardous Materials 386, 121639. https://doi.org/10.1016/j.jhazmat.2019.121639

Percie du Sert, N., Hurst, V., Ahluwalia, A., Alam, S., Avey, M.T., Baker, M., Browne, W.J., Clark, A., Cuthill, I.C., Dirnagl, U., Emerson, M., Garner, P., Holgate, S.T., Howells, D.W., Karp, N.A., Lazic, S.E., Lidster, K., MacCallum, C.J., Macleod, M., Pearl, E.J., Petersen, O.H., Rawle, F., Reynolds, P., Rooney, K., Sena, E.S., Silberberg, S.D., Steckler, T., Würbel, H., 2020. The ARRIVE guidelines 2.0: Updated guidelines for reporting animal research. PLoS Biol 18, e3000410. https://doi.org/10.1371/journal.pbio.3000410 
Pimentel Falcão, M.A., Banderó WALKER, C.I., Rodrigo DISNER, G., Batista-filho, J., Silva SOARES, A.B., Balan-lima, L., Lima, C., Lopes-ferreira, M., 2021. Knockdown of miR-26a in Zebrafish Leads to Impairment of the Anti-Inflammatory Function of TnP in the Control of Neutrophilia. Fish \& Shellfish Immunology. https://doi.org/10.1016/j.fsi.2021.04.029

Pitcher, T.J. (Ed.), 1993. Behaviour of Teleost Fishes, 2nd ed, Fish \& Fisheries Series. Springer Netherlands.

Pleadin, J., Malenica, M., Vah, N., Milone, S., Safti, L., 2015. Survey of aflatoxin B 1 and ochratoxin A occurrence in traditional meat products coming from Croatian households and markets. Food Control 52, 71-77. https://doi.org/10.1016/j.foodcont.2014.12.027

Qi, X., Yang, X., Chen, S., He, X., Dweep, H., Guo, M., Cheng, W.-H., Xu, W., Luo, Y., Gretz, N., Dai, Q., Huang, K., 2015. Ochratoxin A induced early hepatotoxicity: new mechanistic insights from microRNA, mRNA and proteomic profiling studies. Scientific Reports 4, 5163. https://doi.org/10.1038/srep05163

Rahimtula, A.D., Béréziat, J.-C., Bussacchini-Griot, V., Bartsch, H., 1988. Lipid peroxidation as a possible cause of ochratoxin a toxicity. Neurochemical Pharmacology 37, 44694477. https://doi.org/10.1016/0006-2952(88)90662-4

Rani, L., Thapa, K., Kanojia, N., Sharma, N., Singh, S., Grewal, A.S., Srivastav, A.L., Kaushal, J., 2021. An extensive review on the consequences of chemical pesticides on human health and environment. Journal of Cleaner Production 283, 124657. https://doi.org/10.1016/j.jclepro.2020.124657

Reis, C.G., Mocelin, R., Benvenutti, R., Marcon, M., Sachett, A., Herrmann, A.P., Elisabetsky, E., Piato, A., 2020. Effects of $\mathrm{N}$-acetylcysteine amide on anxiety and stress behavior in zebrafish. Naunyn-Schmiedeberg's Arch Pharmacol 393, 591-601. https://doi.org/10.1007/s00210-019-01762-8

Sachett, A., 2021a. Glutathione peroxidase (GPx) activity assessment for zebrafish brain tissue. https://doi.org/10.17504/protocols.io.bsujneun

Sachett, A., 2021b. Glutathione reductase (GR) activity assessment for zebrafish brain tissue. https://doi.org/10.17504/protocols.io.bsuuneww

Sachett, A., 2020. Quantification of nonprotein sulfhydryl groups (NPSH) optimized for zebrafish brain tissue. https://doi.org/10.17504/protocols.io.bjrkkm4w

Sava, V, Reunova, O., Velasquez, A., Harbison, R., J.Sanchez-Ramos, 2006a. Acute neurotoxic effects of the fungal metabolite ochratoxin-A. NeuroToxicology 27 27, 82-92. https://doi.org/10.1016/j.neuro.2005.07.004

Sava, V, Reunova, O., Velasquez, A., Harbison, R., Sanchezramos, J., 2006b. Acute neurotoxic effects of the fungal metabolite ochratoxin-A. NeuroToxicology 27, 82-92. https://doi.org/10.1016/j.neuro.2005.07.004

Sava, V, Reunova, O., Velasquez, A., Sanchez-Ramos, J., 2006c. Can low level exposure to ochratoxin-A cause parkinsonism? Journal of the Neurological Sciences 249, 68-75. https://doi.org/10.1016/j.jns.2006.06.006

Sava, V., Reunova, O., Velasquez, A., Sanchez-Ramos, J., 2006. Can low level exposure to ochratoxin-A cause parkinsonism? Journal of the Neurological Sciences 249, 68-75. https://doi.org/10.1016/j.jns.2006.06.006

Scerbina, T., Chatterjee, D., Gerlai, R., 2012. Dopamine receptor antagonism disrupts social preference in zebrafish: a strain comparison study. Amino Acids 43, 2059-2072. https://doi.org/10.1007/s00726-012-1284-0

Schmidt, L., Heck, N. de V., Ferreira, I., Göethel, G., Somacal, S., Emanuelli, T., Rodrigues, E., Garcia, S.C., Welke, J.E., Augusti, P.R., 2020. Ochratoxin A presence in Cabernet Sauvignon wine changes antioxidant activity in vitro and oxidative stress markers in vivo. Food Additives \& Contaminants: Part A 37, 1755-1764. https://doi.org/10.1080/19440049.2020.1802067

Sorrenti, V., Di Giacomo, C., Acquaviva, R., Barbagallo, I., Bognanno, M., Galvano, F., 2013. Toxicity of Ochratoxin A and Its Modulation by Antioxidants: A Review. Toxins 5, 1742-1766. https://doi.org/10.3390/toxins5101742 
Stoev, S.D., 2010. Studies on carcinogenic and toxic effects of ochratoxin A in chicks. Toxins 2, 649-664. https://doi.org/10.3390/toxins2040649

Sun, W., Han, Z., Aerts, J., Nie, D., Jin, M., Shi, W., Zhao, Z., De Saeger, S., Zhao, Y., Wu, A., 2015. A reliable liquid chromatography-tandem mass spectrometry method for simultaneous determination of multiple mycotoxins in fresh fish and dried seafoods. Journal of Chromatography A 1387, 42-48. https://doi.org/10.1016/j.chroma.2015.01.071

Tao, Y., Xie, S., Xu, F., Liu, A., Wang, Y., Chen, D., Pan, Y., Huang, L., Peng, D., Wang, X., Yuan, Z., 2018. Ochratoxin A: Toxicity, oxidative stress and metabolism. Food and Chemical Toxicology 112, 320-331. https://doi.org/10.1016/j.fct.2018.01.002

Tola, M., Kebede, B., 2016. Occurrence, importance and control of mycotoxins: A review. Cogent Food \& Agriculture 2. https://doi.org/10.1080/23311932.2016.1191103

Tschirren, L., Siebenmann, S., Pietsch, C., 2018. Toxicity of Ochratoxin to Early Life Stages of Zebrafish (Danio rerio). Toxins 10, 264. https://doi.org/10.3390/toxins10070264

United Nations, 2017. World population projected to reach 9.8 billion in 2050, and 11.2 billion in 2100 - says UN. Presented at the 2017 Revision of World Population Prospects.

v. d. Stegen, G., Jörissen, U., Pittet, A., Saccon, M., Steiner, W., Vincenzi, M., Winkler, M., Zapp, J., Schlatter, Chr., 1997. Screening of European coffee final products for occurrence of ochratoxin A (OTA). Food Additives and Contaminants 14, 211-216. https://doi.org/10.1080/02652039709374518

Valadas, J., Mocelin, R., Sachett, A., Marcon, M., Zanette, R.A., Dallegrave, E., Herrmann, A.P., Piato, A., 2019. Propiconazole induces abnormal behavior and oxidative stress in zebrafish. Environ Sci Pollut Res 26, 27808-27815. https://doi.org/10.1007/s11356019-05977-3

Vandenberg, L.N., Colborn, T., Hayes, T.B., Heindel, J.J., Jacobs, D.R., Lee, D.-H., Shioda, T., Soto, A.M., vom Saal, F.S., Welshons, W.V., Zoeller, R.T., Myers, J.P., 2012. Hormones and Endocrine-Disrupting Chemicals: Low-Dose Effects and Nonmonotonic Dose Responses. Endocr Rev 33, 378-455. https://doi.org/10.1210/er.2011-1050

VARGA, J., KISS, R., MÁTRAI, T., MÁTRAI, T., J.TÉREN, 2014. Detection of Ochratoxin A in Hungarian Wines and Beers DETECTION OF OCHRATOXIN A IN HUNGARIAN. Acta Alimentaria 34, 381-392. https://doi.org/10.1556/AAlim.34.2005.4.6

Vega, M., Ríos, G., von Baer, D., Mardones, C., Tessini, C., Herlitz, E., Saelzer, R., Ruiz, M.A., 2012. Ochratoxin A occurrence in wines produced in Chile. Food Control 28, 147-150. https://doi.org/10.1016/j.foodcont.2012.04.032

Woo, C.S.J., Wan, M.L.Y., Ahokas, J., El-Nezami, H., 2013. Potential endocrine disrupting effect of ochratoxin A on human placental 3 3 -hydroxysteroid dehydrogenase/isomerase in JEG-3 cells at levels relevant to human exposure. Reproductive Toxicology 38, 4752. https://doi.org/10.1016/j.reprotox.2013.02.034

World Health Organization (Ed.), 2006. Pesticide residues in food - 2004: toxicological evaluations : joint meeting of the FAO Panel of Experts on Pesticide Residues in Food and the Environment and the WHO Core Assessment Group, Rome, 20-29 September 2004. World Health Organization, Geneva, Switzerland.

Xin, H., Stone, R., 2008. TAINTED MILK SCANDAL: Chinese Probe Unmasks High-Tech Adulteration With Melamine. Science 322, 1310-1311. https://doi.org/10.1126/science.322.5906.1310

Yoon, S., Cong, W.T., Bang, Y., Lee, S.N., Yoon, C.S., Kwack, S.J., Kang, T.S., Lee, K.Y., Choi, J.K., Choi, H.J., 2009. Proteome response to ochratoxin A-induced apoptotic cell death in mouse hippocampal HT22 cells. NeuroToxicology 30, 666-676. https://doi.org/10.1016/j.neuro.2009.04.013 


\section{SUPPLEMENTAL MATERIAL}

\section{Ochratoxin A causes behavioral and neurochemical changes in adult zebrafish}

Jéssica Valadas ${ }^{\mathrm{a}}$, Adrieli Sachett ${ }^{\mathrm{a}}$, Matheus Marconc ${ }^{\mathrm{c}}$, Leonardo M. Bastos ${ }^{\mathrm{b}}$, Angelo

Piato $^{\mathrm{a}, \mathrm{b} *}$

a Programa de Pós-Graduação em Neurociências, Instituto de Ciências Básicas da Saúde, Universidade Federal do Rio Grande do Sul (UFRGS), Porto Alegre, RS, Brazil

${ }^{\mathrm{b}}$ Departamento de Farmacologia, Instituto de Ciências Básicas da Saúde, Universidade Federal do Rio Grande do Sul (UFRGS), Porto Alegre, RS, Brazil

${ }^{c}$ Departamento de Bioquímica, Farmacologia e Fisiologia, Universidade Federal do Triângulo Mineiro (UFTM), Uberaba, MG, Brazil

Distance

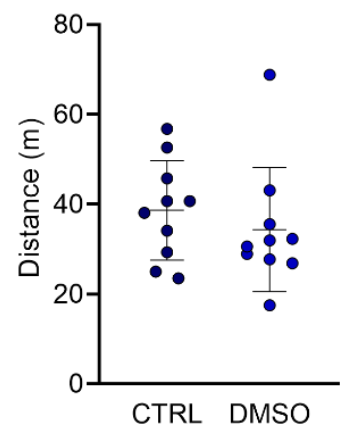

Mean Speed

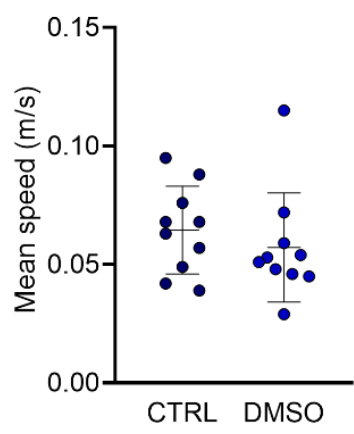

Crossings

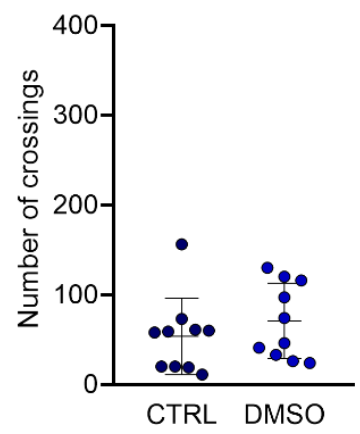

Freezing episodes

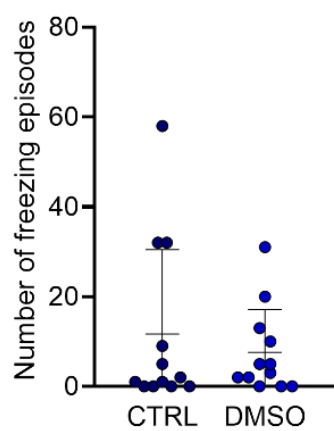

Absolute Turn Angle

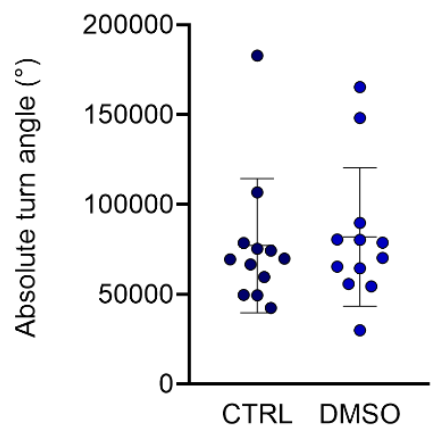

Time-freezing

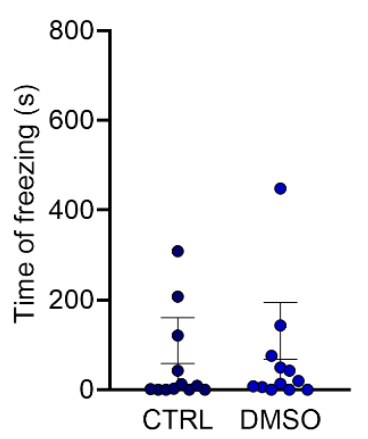

Supplementary material 1. Comparison between CRTL (sodium chloride) vs. DMSO (dimethyl sulfoxide) on behavior parameters at open tank test. Data are expressed as mean \pm standard deviation (S.D.). $n=10$. Student's t-test. ${ }^{*} \mathrm{p}<0.05$. 
TBARS

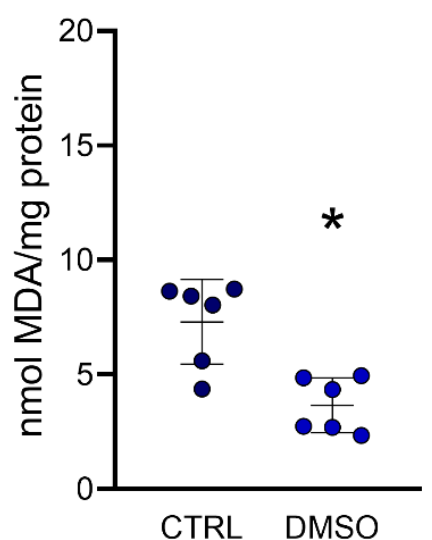

NPSH

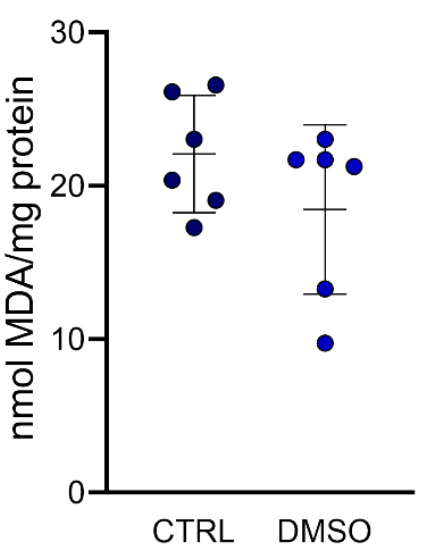

Supplementary material 2. Comparison between CRTL (sodium chloride) vs. DMSO (dimethyl sulfoxide) on neurochemical parameters. Data are expressed as mean \pm standard deviation (S.D.). $\mathrm{n}=6$. Student's t-test. ${ }^{*} \mathrm{p}<0.05$. 